\title{
Differential Evolution Algorithm for House Size Determination in a Poultry Production
}

\author{
Puripat Sriputthimeth $^{\mathrm{a}}$, Kanchana Sethanan $^{\mathrm{a},{ }^{*}, \text { Karn Moonsri }^{\mathrm{a}}}$ \\ ${ }^{a}$ Research Unit on System Modeling for Industry, Industrial Engineering Department, \\ Faculty of Engineering, Khon Kaen University, Khon Kaen 40002, Thailand \\ *Corresponding Author: ksethanan@gmail.com
}

\begin{abstract}
This study focuses on determining size (or capacity) and an appropriate number of hen houses for raising chicks in each week along the planning horizons. The chicks are raised in pullet farms until the age of 17 weeks. These pullets are then moved to hen houses and fed to a prescribed body weight to support egg production, and remain in the hen houses until they reach 75 weeks of age. Normally, the capacities of the pullet and hen houses are heterogeneous depending on the level of investment of contract farms. The complexity of poultry production that there are different sizes of pullet and hen houses then the different ages of hen could be mixed then the production cost get higher because hen will be slaughtered earlier than their ages. The problem is to determine how many hen houses to set up, new hen house to build and determine the capacity of them to cover changing trends in demand and/or cost. The purposed DE algorithm was developed to minimize the total cost including cost of open hen house, cost of ordering hen and cost of mix aged hen and also meet the demands over the planning horizons. Finally the metaheuristics using differential evolution (DE) was developed then the solutions compared to the lower bound. The results of $\mathrm{DE}$ algorithms have heuristics performance $87.28 \%$ to $92.73 \%$ and the average is $89.69 \%$
\end{abstract}

Keywords: Differential Evolution, Heuristics Algorithm

\section{Introduction}

Egg production industries in Thailand are one of important agricultural product 95\%-99\% of egg production in Thailand was sold domestically and 1-5\% exported. The egg production in Thailand have increasing trend of demand during the years 2010-2014, the hen growth rate increased at 4.77 percent per year. ${ }^{(1)}$

This research was motivated by the production firm in northeastern Thailand. The supply chain of the egg production starts from purchasing chicks from hatchery weekly. Then they transferred to the contract farm which different capacity of hen houses. Chicks stay until they are 17 weeks of age. After that they transferred to laying hen houses which different capacity for harvesting eggs, and remain in the hen house until the age of 75 weeks. After that they moved the hen to slaughter at slaughter house. The hen houses have to strip of all organic matter and sanitized before other hens enter. The eggs collection procedure is that eggs are collected and sent to the egg processing center. In order to washed, inspected, and then graded for packing and selling

We develop a model to minimize total costs which include open hen house cost, ordering of hen cost and loss cost from mixing hen with different ages. The goal is to select the number and capacities of the new hen house to open so that all hen demand is satisfied and also minimize total cost. We use metaheuristics Differential Evolution algorithms to solve the problem.

\section{Literature Review}

This research focuses to the allocation problem with the allocated hen into the Hen houses. Therefore review research that looks into the allocation problem or egg industries with similar solutions and applied Meta-heuristic on the allocation problem.

Demircan et al. (2010) studies the different capacity laying hen farms in Afyon province in Turkey. The study shown that the large farms had the highest egg yield and lower production cost and a better feed efficiency. It was 
found that profit margin increased as the capacity of the farm increased ${ }^{(1)}$. Emam and Hassan (2010) studied poultry egg production in the open system in Khartoum State. They study the main factors production cost and compare between production costs, gross margins in different farm types and sizes. A Questionnaire used to collect the data. The highest gross profit was obtained in large farm sizes. The large size farm was more efficient than other sizes and type of the farms ${ }^{(3)}$.

Helfand and Levine (2004) Levine study the relationship between farm size and efficiency. Data Envelopment Analysis (DEA) was used to analyze. They found that the relationship between farm size and efficiency is found to be non-linear. Technical efficiency of farms decreased at the beginning and then increased with the increasing farm size ${ }^{(4)}$.

Sethanan et al.(2013) focused on determining the appropriate size of pullet and hen house by using neighborhood search and genetic algorithms to determine the number of pullet and hen houses ${ }^{(5)}$. Sethanan et al. applied Whittin's algorithm to planning the chicks to allocate to pullet and hen houses ${ }^{(6)}$. Boonmee et al. (2013) studied the decision making to fully utilize vehicle capacity in transporting eggs from contract farm to distribution center and from distribution center to the customers. The study shown cost reduction from the used fewer vehicles, shorter distances ${ }^{(7)}$.

Amiri (2006) studied designing a distribution network in supply chain. Facility and demand allocation problems usually involve the cost of opening and operating cost and the transportation costs. As known capacitated warehouse location problem involves locating a given number of warehouses to satisfy customer demands. They developed mixed integer programming model and provide an efficient heuristic solution procedure for this supply chain system problem $^{(8)}$. In general the problems involve a set of distributed customers and a set of facilities that serve customer demand. Distances, times and costs are measures of the problem (Melo et al. ,2009) ${ }^{(9)}$

The DE algorithm was first proposed by Storn and Price (1997) for continuous optimization ${ }^{(10)}$. DE has been successfully applied in allocation problem fields, such as Worasan (2014) using differential evolution (DE) was developed to solve larger, more realistic problems on transportation problem with pickup and delivery with the objective to of minimize transportation costs and results obtained from this study show that the DE algorithm provides better total cost values than that of the firm's current practice by 0.00 to $17.60 \%{ }^{(11)}$. Saenkaeo (2015) developed differential evolution for minimize the total transportation cost in vehicle routing problem (VRP) ${ }^{(12)}$.

Dechampai (2015) propose hybrid differential evolution algorithm for capacitated VRP with flexibility of mixing pickup and delivery services and the maximum duration of a route in poultry industry. The results obtained from this study show that the MESOMDE_G-Q-DVRP-FD algorithm provides lower total cost values than that of the firm's current practice by $7.59-31.28$ and $0.84-13.15 \%$ etc $^{(13)}$.

Sethanan and Pitakaso (2016) presents DE algorithm to solve the generalized assignment problem (GAP) with the objective to minimize the assignment cost and applied three local search : shifting, exchange, and k-variable move algorithms for improve DE algorithm and competition performance with Bee algorithm (BEE) and Tabu search algorithm (TABU) ${ }^{(14)}$

From the review of the literature, it was found that the available models could not be applied to the case. This study mainly finds the number of new hen houses to build and the capacity of them to minimize total cost. The differential evolution algorithm was used to solve the problem will be described in the next section.

\section{Differential Evolution Algorithm}

In this section, we developed model using Differential Evolution algorithm. The objective is to minimize total cost consisting three components: cost of open hen house, cost of ordering hen and cost of mix aged hen. The purposed method uses Differential Evolution with decode method by rank order value (ROV) to calculate the fitness value of DE vector used equation (1).

\subsection{Objective Function:}

$$
\begin{aligned}
& \text { Minimize } Z= \\
& \sum_{i=1}^{I} \sum_{t=1}^{T} a x_{i t}+\sum_{j=1}^{J} \sum_{t=1}^{T} a x^{\prime}{ }_{j t}+\sum_{i=1}^{I} \sum_{t=1}^{T} b_{i} y_{i t}+\sum_{j=1}^{J} \sum_{t=1}^{T} b{ }^{\prime}{ }_{j} y{ }_{j t}+ \\
& \sum_{i=1}^{I} \sum_{t=1}^{T} d q_{i t+1}+\sum_{j=1}^{J} \sum_{t=1}^{T} d q^{\prime}{ }_{j t+1}
\end{aligned}
$$




\section{$\underline{\text { Parameters }}$}

$a$

$b_{i} \quad$ Cost open of old hen houses $i$ (baht)

$b_{j}^{\prime} \quad$ Cost open of new hen houses $j$ (bath)

capH $_{i} \quad$ Capacity of old hen houses $i$ (hen)

$\mathrm{capNH}_{j} \quad$ Capacity of new hen houses $j$ (hen)

$d \quad$ Cost for mixed hen in period (bath)

$D_{t} \quad$ Demand hen of period $t$ (hen/week)

$\underline{\text { Decision variables }}$

$x_{i t} \quad$ Number hens for allocating to old hen houses $i$ on period $t$

$x_{i t}^{\prime} \quad$ Number hens for allocating to new hen houses $j$ on period $t$

$q_{i t+1} \quad$ Number hens for allocating to old hen houses $i$ on period $t+1$

$q_{j t+1}^{\prime} \quad$ Number hens for allocating to new Binary variables

$\begin{array}{ll}y_{i t} & =1 \text {, if open old hen houses } i \text { on } \\ & \text { period } t \text { and } 0 \text { otherwise } \\ y^{\prime}{ }_{j t} & =1, \text { if open new hen houses } j \text { on } \\ & \text { period } t \text { and } 0 \text { otherwise }\end{array}$

\subsection{Procedure: DE Algorithm}

\section{Begin}

2. Define $D_{t}, \operatorname{capH}_{i}, \mathrm{capNH}_{j}, C R, N P$ and Tmax

3. Generate initial vector $x_{i, G}$ by random value between $[0,1]$

4. While (not terminating condition) do

5. For $n=1$ to NP

6. Mutation operation: for the vectors $x_{i, G}$ randomly select three vectors $X_{r 1, G}, X_{r 2, G}$ and $X_{r 3, G}$ then add the weighted difference of two vectors according to equation

$$
V x_{n, G+1}=X_{r 1, G}+F\left(X_{r 2, G}-X_{r 3, G}\right)
$$

7. Recombination operation: the trial vectors $U_{x n, G+1}$ are developed from target vector and mutant vector according to the equation below.

$$
U_{x n, G+1}=\left\{\begin{array}{l}
V_{x n, G+1} \text { if }(\operatorname{rand}(j)<C R) \text { or } j=\operatorname{rnbr}(I) \\
x_{n, G} \text { if }(\operatorname{randb}(j) \geq C R) \text { or } j \neq \operatorname{rnbr}(I)
\end{array}\right.
$$

Rand $(j)$ is a random number between [0, 1].If $\operatorname{Rand}(j)<C R$ use the mutant vectors as a trial vectors $U_{x n, G+1}$

8. The trial vectors $U_{x n, G+1}$ are normalized to value between $[0,1]$ by equation below.

$$
U x_{n, G}^{*}=\frac{\text { MaxTarget }- \text { MinTarget }}{\operatorname{Max}_{n}-\operatorname{Min}_{n}} \times\left(U x_{n, G}-\operatorname{Min}_{n}\right)
$$

9. Evaluate the fitness value: the decode method we used rank order value by ascending order of target vectors and trial vectors. The vectors $x_{i, G}$ were used to allocate the demand of hen $D_{t}$ to the old hen house $\mathrm{capH}_{i}$ and the new hen houses $\operatorname{capNH}_{j}$. For example, there are demand of hens 5 periods and the old hen houses 7 houses. The demand of period to allocate is follow by 1-2-5-4-3 and allocated to the old hen houses follow by 6-1-2-4-5-7-3 as show in the Fig. 1. And the Fig. 2. show that how demand of hens allocated to the old hen houses on period $=1, x_{i t}$ was shown. Do until all demand period was satisfied. Then calculated objective function by equation (1) 


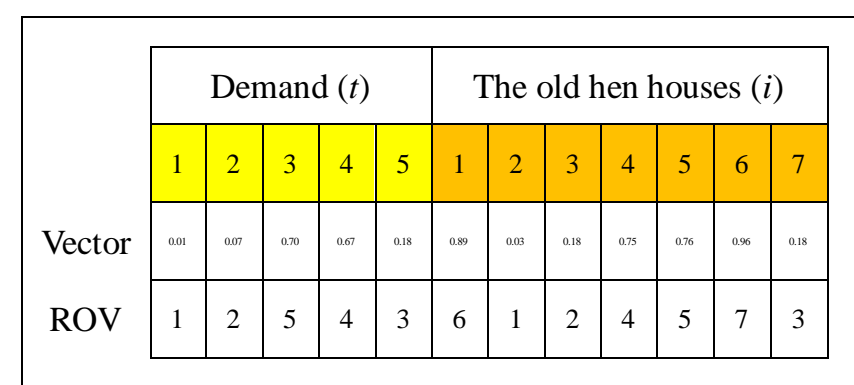

Fig. 1. An example of decoding method by ROV

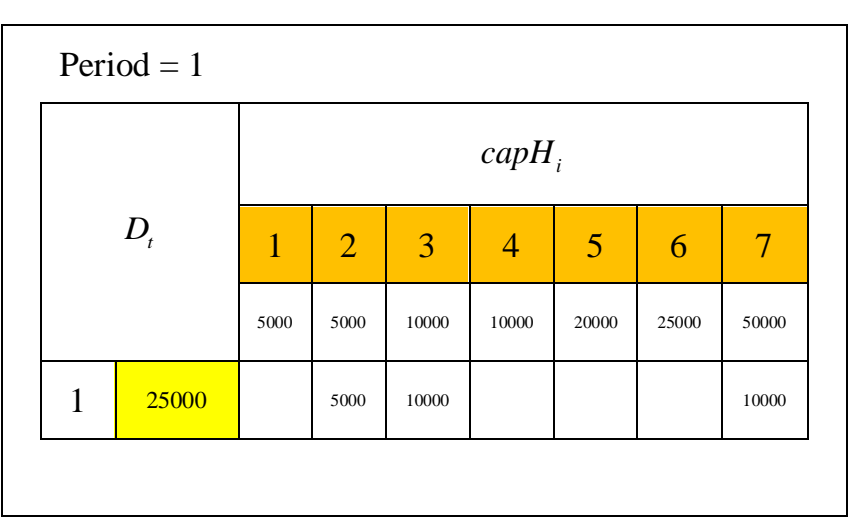

Fig. 2. An example hen allocated to hen house

for period $=1$

10. Selection operation: the target vectors $x_{i, G}$ is compared with the trial vectors $U_{x n, G+1}$ and the one with the lowest cost is admitted to the next generation

\section{Loop until max_iteration or Tmax.}

\section{Numerical Experiments}

The heuristics performance of the solution obtained by the purposed DE algorithm was compared to the lower bound. The value parameters of different data types we use to test the performance of heuristics were shown on Table 1. Eight types of data characteristics were generated and five test problems for each of them.

Table 1. Values of parameters of the different data types

\begin{tabular}{|c|c|c|c|}
\hline $\begin{array}{c}\text { Data } \\
\text { type }\end{array}$ & $\begin{array}{c}\text { number of } \\
\text { periods }\end{array}$ & $\begin{array}{c}\text { number of old } \\
\text { hen houses }\end{array}$ & $\begin{array}{c}\text { number of new } \\
\text { hen houses }\end{array}$ \\
\hline 1 & 15 & 15 & 18 \\
\hline 2 & 15 & 15 & 30 \\
\hline 3 & 15 & 25 & 18 \\
\hline 4 & 15 & 25 & 30 \\
\hline 5 & 20 & 15 & 18 \\
\hline
\end{tabular}

Table 1. Values of parameters of the different data types

\begin{tabular}{|c|c|c|c|}
\hline $\begin{array}{c}\text { Data } \\
\text { type }\end{array}$ & $\begin{array}{c}\text { number of } \\
\text { periods }\end{array}$ & $\begin{array}{c}\text { number of old } \\
\text { hen houses }\end{array}$ & $\begin{array}{c}\text { number of new } \\
\text { hen houses }\end{array}$ \\
\hline 6 & 20 & 15 & 30 \\
\hline 7 & 20 & 25 & 18 \\
\hline 8 & 20 & 25 & 30 \\
\hline
\end{tabular}

The purposed DE algorithm, was developed using Visual Basic programing on Intel ${ }^{\circledR}$ Core $^{\mathrm{TM}}$ i5 processor(2.9-Ghz clock), with 16 GBytes of RAM. In order to test the model, the performance of the purposed DE algorithm measured by heuristic performance (HP) of the solution. The purposed DE algorithms was evaluated and presented below.

$$
\begin{aligned}
& \text { Let } \quad H P \quad=\frac{\text { sol_LB }_{\text {Sol }}}{\text { Sol } h e u} \times 100 \% \\
& \text { Where; } \quad \begin{array}{ll}
H P & =\text { heuristic performace } \\
\text { Sol_LB } & =\text { the solution obtained } \\
& \text { from the lower bound } \\
\text { sol_heu } & =\text { the solution obtained } \\
& \text { from the purposed DE } \\
& \text { algorithm }
\end{array}
\end{aligned}
$$

For each data type, five different test problems were generated. The results of DE algorithm compared to lower bound are presented in Table 2. And computation times of them are shown on Table 3. That means the DE algorithm was good compared to the lower bound.

Table 2. Computational Result for all Data Types

\begin{tabular}{|c|c|c|c|c|c|}
\hline \multirow{2}{*}{$\begin{array}{c}\text { Data } \\
\text { Type }\end{array}$} & \multicolumn{3}{|c|}{$\begin{array}{c}\text { Total Cost } \\
\text { (Million Bath) }\end{array}$} & \multicolumn{2}{c|}{ HP (\%) } \\
\cline { 2 - 6 } & \multirow{2}{*}{$\begin{array}{c}\text { Lower } \\
\text { Bound }\end{array}$} & \multicolumn{2}{|c|}{ DE } & \multicolumn{2}{c|}{ DE } \\
\cline { 3 - 6 } & Best & Mean & Best & Mean \\
\hline 1 & 4.50 & 4.80 & 4.86 & 93.81 & 92.57 \\
\hline 2 & 4.42 & 4.85 & 4.87 & 91.18 & 90.90 \\
\hline 3 & 1.32 & 1.46 & 1.47 & 90.45 & 89.75 \\
\hline 4 & 1.32 & 1.47 & 1.49 & 89.91 & 89.03 \\
\hline 5 & 7.16 & 7.68 & 7.72 & 93.20 & 92.73 \\
\hline 6 & 6.92 & 7.58 & 7.64 & 91.24 & 90.54 \\
\hline 7 & 3.70 & 4.18 & 4.23 & 88.61 & 87.62 \\
\hline 8 & 3.70 & 4.22 & 4.24 & 87.85 & 87.28 \\
\hline
\end{tabular}


Table 3. Computational times for all Data Types

\begin{tabular}{|c|c|c|c|}
\hline \multirow{2}{*}{ Data Type } & \multicolumn{3}{|c|}{ Computation time(SEC) } \\
\cline { 2 - 4 } & \multirow{2}{*}{ lower bound } & \multicolumn{2}{|c|}{ DE } \\
\cline { 2 - 4 } & & Best & Mean \\
\hline 1 & 0.40 & 21.11 & 21.14 \\
\hline 2 & 0.12 & 27.34 & 27.36 \\
\hline 3 & 0.20 & 23.81 & 23.84 \\
\hline 4 & 0.30 & 30.18 & 30.20 \\
\hline 5 & 0.34 & 27.28 & 27.32 \\
\hline 6 & 0.40 & 31.08 & 31.11 \\
\hline 7 & 0.44 & 28.44 & 28.51 \\
\hline 8 & 0.24 & 31.67 & 31.75 \\
\hline
\end{tabular}

\section{Conclusions}

In this paper. We propose DE algorithm to solve a problem to find the capacity of old hen houses to set up and capacity of new hen houses to build. We use DE algorithm to allocate hen to old hen houses and new hen houses. The performance of algorithms was measured by heuristics performance (HP) by compared the total cost of them. The solutions compared to the lower bound. The results of $\mathrm{DE}$ algorithms have heuristics performance $87.28 \%$ to $92.73 \%$ and the average is $89.69 \%$ and the computation time is less than one minute.

\section{Acknowledgement}

The authors would like to thank for Mo Din Dang White Elephant Scholarship, Faculty of Engineering, Khon Kaen University, Thailand.

\section{References}

(1) OAE (Office of Agricultural Economics).Available from:<http://www.oae.go.th/download/document_te ndency/journalofecon2558.pdf $>$; 2015, (accessed 15.11.15).

(2) Demircan, V., Yilmaz, H., Dernek, Z., Bal, T., GÜL, M., \& Koknaroglu, H. Economic analysis of different laying hen farm capacities in Turkey. Agric. Econ.-Czech, 56(2010), 10. 2010

(3) Emam, A. A., \& Hassan, A. M. Economics of egg poultry production in Khartoum State with emphasis on the open-system-Sudan. African Journal of Agricultural Research, 5(18), 2491-2496. 2010

(4) Helfand, S. M., \& Levine, E. S. Farm size and the determinants of productive efficiency in the Brazilian Center West. Agricultural Economics,31(2-3), 241-249. 2004

(5) Sethanan, K., Theerakulpisut, S., Pakdeeying, W., \& Neungmatcha, W. House size determination for poultry production. Advanced Science Letters, 19(12), 3703-3707.1. 2013

(6) Sethanan, K., Jamrus, T., \& Boonthavee, P. Solving production scheduling of egg production in hen farms with capacity of slaughterhouse by heuristic algorithms. IACSIT International Journal of Engineering and Technology, 5, 50-53.1. 2013

(7) Boonmee, A., Sethanan, K., \& Theerakulpisut, S. Optimizing vehicle utilization for chicken egg logistics management. Advanced Science Letters, 19(12), 3708-3712. 2013

(8) Amiri, A. Designing a distribution network in a supply chain system: Formulation and efficient solution procedure. European Journal of Operational Research, 171(2), 567-5761. 2006

(9) Melo, M. T., Nickel, S., \& Da Gama, F. S. Dynamic multi-commodity capacitated facility location: a mathematical modeling framework for strategic supply chain planning. Computers \& Operations Research, 33(1), 181-208. 2006

(10) Price, V. Kenneth and Strom, M. Rainer Differential evolution: a simple evolution strategy for fast optimization. Dr. Dobb's Journal, 22, 18-24 and 78. 1997

(11) Worasan, K., Sethanan, K., Dairy transportation problem with no mixing of raw milk and time windows constraints. Proceedings of the Asia Pacific industrial engineering and management system. 2014

(12) Saenkaeo, S. Heuristics algorithm for managing the employee transportation for a large industry. Master of Engineering thesis in Industrial Engineering, Graduate School, Khon Kaen University Thailand.2015

(13) Dechampai, D., Tanwanichkul, L., Sethanan, K., \& Pitakaso, R. A differential evolution algorithm for the capacitated VRP with flexibility of mixing pickup and delivery services and the maximum duration of a route in poultry industry. Journal of Intelligent Manufacturing, 1-20. 2015

(14) Sethanan, K., \& Pitakaso, R. Improved differential evolution algorithms for solving generalized assignment problem. Expert Systems with Applications,45, 450-459. 2016 